\title{
Pudor y representación. La raza mapuche, la desnudez y el disfraz ${ }^{1}$
}

\section{Modesty and Representation. Mapuche Race, Nakedness and Disguise}

\author{
André Menard \\ Departamento de Antropología, Facultad de Ciencias Sociales, \\ Universidad de Chile. Santiago \\ peromenard@gmail.com
}

Resumen • El presente artículo plantea un estudio sobre la función que ha tenido, sobre todo a principios del siglo XX, el problema del cuerpo, la sexualidad y la noción de pudor en la representación de la «raza» mapuche. Para ello se explorarán, primero, los vínculos entre la pornografía actual y la fotografía etnográfica. Segundo, el lugar que ocupaban el pudor y la sexualidad en los debates sobre el "verdadero carácter de la raza araucana». Por último, trataremos la relación entre la desnudez, la vestimenta y el disfraz en su relación con esta pregunta por la «verdad» de una representación etnográfica o fotográfica de la raza.

Palabras clave: raza, pudor, mapuche, cuerpo, representación.

Abstract - The following article presents a study of the functions that the notions of body, sexuality and modesty, in the representation of the Mapuche «race», has had especially since the beginning of the twentieth century. The article will, first, explore the connections between contemporary pornography and ethnographic photography. Secondly, it will extend into the places that modesty and sexuality occupy in the debates about the "true character of the Araucanian race». Finally, it will treat the relation between nakedness, costume and disguise and their relation with the question of «truth» in an ethnographical or photographic representation of race.

Keywords: race, modesty, mapuche, body, representation.

1 Trabajo realizado en el marco del proyecto FONDECYT núm. 3080028: «La noción de raza en el discurso político mapuche, y sobre lo mapuche, en el siglo XX». Responsable de la investigación, André Menard. 


\section{PREÁMBULO}

A fines de agosto del 2006 circuló un mail colectivo titulado «La Sociedad Secreta Reche, al mundo Mapuche». En él se atacaba crudamente a las realizadoras de cierto proyecto teatral de la época llamado Malen Weichafe (mujeres guerreras) y se adjuntaba un par de fotografías para apoyar las acusaciones. En ellas las Malen Weichafe aparecían desnudas, con sus cuerpos pintados y enarbolando lanzas junto a un rehue. El autor se indignaba ante esta conjunción de desnudez y espectáculo étnico:

Ante este insulto hacia nuestra Cultura Mapuche, debemos señalar que desde que tenemos uso de razón nuestra cultura siempre a [sic] llevado ropa y la ropa crea una distinción en lo político, social y espiritual, así nos lo han enseñado nuestros ancestros, de igual forma nunca una Machi se ha mostrado desnuda frente a su Rewe en una ceremonia, ni ordenara algo por el estilo a los asistentes a un nguillatun.

Tras esta deploración de la desnudez, el autor reivindicaba una estricta división de roles de género entre hombres y mujeres mapuche, explicando que la cultura mapuche "no es una cultura machista, ni feminista, cada uno sabe su labor para mantener el equilibrio del hogar, en este universo que se llama Ruka». Y finalizaba introduciendo el problema general de la representación: «Los Mapuches somos implacables y a veces se nos podría tachar como racistas, pero es que no permitiremos a nadie que juegue con algo sagrado como es nuestra cultura, o lleguen sin que nadie los haya invitado a representarnos».

Pese a lo grotesco y aparentemente anacrónico de esta declaración, nos interesa remarcar cómo, tras el problema general de la representación racial o étnica, persiste una invocación moral del pudor ante la exposición de unos cuerpos desnudos. Se manifiestan así las posibles líneas de continuidad entre los debates antropológicos que hace cien años especulaban sobre las disposiciones carnales y morales de las razas, y las dimensiones normativas que pueden adquirir hoy día nociones como las de cultura, cosmovisión o identidad. Si bien el presente artículo se enfoca en esos primeros debates etnológicos, sus argumentos permiten vislumbrar la vigencia actual de estas antiguas preocupaciones por los límites de la representatividad.

En lo que sigue exploraremos algunos de los imaginarios fotográficos y etnográficos, con que a fines del siglo XIX y principios del XX, se pretendía representar la «raza araucana». Veremos los conflictos y debates que los opusieron, poniendo especial atención en el rol que en ellos jugó el problema del pudor como clave para entender la cuestión de la sexualidad, el erotismo o el deseo en estas representaciones. En este marco, y para comprender las relaciones más generales entre la representación de un sujeto étnico o racial y la distribución del pudor, nos detendremos un momento en las analogías y desplazamientos entre los imaginarios etnográficos más clásicos y la pornografía actual.

\section{ETNOGRAFÍA Y PORNOGRAFÍA}

El episodio de la Sociedad Secreta Reche contra las Malen Weichafe trata de la producción fotográfica de un escándalo. Y si insistimos en esa dirección accedemos al campo de la pornografía entendida como una puesta en espectáculo del pudor, así como la 
industria que ha elaborado los modos de producción que permiten sacarle rendimiento. Digamos, en primer lugar, que más allá de las características formales que identificaremos a continuación, la pornografía escapa a toda definición "definitiva», es decir a la asignación de un número limitado y exclusivo de cualidades. De ahí que antes de remitir a un contenido positivo, la pornografía funcione como un operador moral: clase moral vacía que permite establecer, por contraste, el ámbito de las decencias.

La relación que nos interesa explorar ahora es la de la pornografía actual (entendida como un modo hegemónico y más o menos codificado de producción de imágenes del cuerpo) con cierta fotografía etnográfica de fines del siglo XIX y principios del XX. Para ello proponemos una hipótesis: la pornografía — en su forma actual y hegemónica- articula dos dimensiones de la fotografía etnográfica tradicional. Por un lado, una dimensión funcional: se trata de una producción orientada más a la producción de un efecto (excitación sexual) que a la narración de una historia o a la instalación de unos nombres propios (de los personajes, de los actores, del director). Por otro, una dimensión formal: la pornografía puede ser descrita como la puesta en escena de un funcionamiento. Y esto mediante el uso preferente del close-up y de la presentación del cuerpo como un lugar fragmentado. De ahí cierta asepsia visual y cierto higienismo en la estética pornográfica más actual y canónica. Este tratamiento maquínico del cuerpo (y que puede ser leído como una transposición al plano genital del cuerpo y sus mucosas, de la estética explorada a principios del siglo XX por filmes como Metrópolis de Fritz Lang o Tiempos Modernos de Charles Chaplin) posibilita la instauración del mercado pornográfico, hoy vigente como un enorme aparato de clasificación. Basta visitar cualquier sitio de pornografía en Internet para constatar que gran parte de su capital de placer pasa por la puesta en escena de su potencia clasificatoria. La fragmentación del cuerpo en partes, funciones y atributos, se despliega en todo un abanico de combinaciones posibles catalogadas según tipos de postura, de indumentaria, de instrumentos, de secreciones, de géneros y, dato importante para el tema de este artículo, de razas².

Una consecuencia de este modo pornográfico de producción de imágenes del cuerpo tiene que ver con el destino del sujeto. Se puede decir que uno de los motores libidinales de la pornografía se basa en la transformación del sujeto en un objeto pornográfico. Desde una fenomenología bataillana se podría incluso pesquisar el rastro de una tenue línea de erotismo al interior del fenómeno pornográfico entendido como un «arte» de mancillar al sujeto. ${ }^{3}$ En este proceso la subjetividad no estaría plenamente excluida, sino que persistiría bajo la forma inferior del combustible. Y así como la pornografía consume al sujeto en la producción del objeto porno, la etnografía (y disciplinas conexas como la criminología o la psiquiatría) opera en forma análoga al transformar al sujeto en objeto étnico.

Ahora bien, la particularidad del producto pornográfico es que logra articular dos dimensiones que en el campo etnográfico corrían por carriles separados. Por un lado, reconocemos una faceta en la foto etnográfica que podemos calificar «formalmente pornográfica». Esta responde a la dimensión analítica del paradigma raciológico que la guiaba. Así, el proceso ya señalado de transformación del sujeto en objeto étnico corresponde a

En este sentido resulta interesante constatar que la categoría «interracial», figura entre las más canónicas del porno actual, principalmente en el caso de las producciones dirigidas al mercado norteamericano.

«La belleza importa en primer lugar por el hecho de que la fealdad no puede ser mancillada, y porque la esencia del erotismo es la mancilla. [...] Cuanto mayor es la belleza, más profunda es la mancilla» (citado en Didi-Huberman, 2005: 115). 
su transformación en un objeto de conocimiento de carácter general, definible como un conocimiento zoológico de lo humano. Aparecen aquí las técnicas de análisis y representación antropométrica, técnicas en las que reencontramos el procedimiento formalmente pornográfico de recorte visual de los cuerpos (lámina 1). Desde la pregunta por el humanismo de la ciencia o de la pornografía, podemos hablar de un tratamiento del sujeto que en definitiva no es ni humano ni inhumano. Es como si se abriera al interior de lo humano una zona de indeterminación en que se busca determinar los grados de animalidad que separan internamente a lo humano. Giorgio Agamben hablaría de una máquina antropológica.

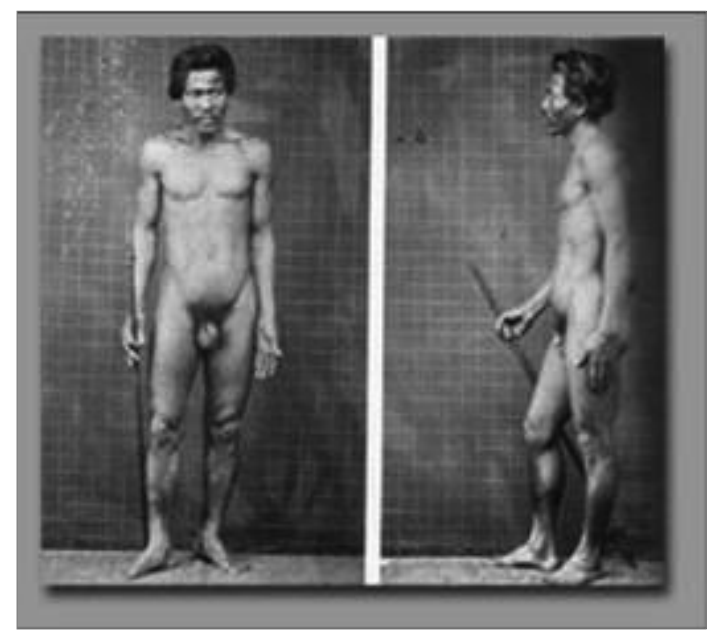

1. John Lamprey. Hombre malayo, 1868-1969. Fuente: Elizabeth Edwards (ed.). (1992). Anthropology and Photography (1860-1920). New Haven: Yale University Press.

Esta zona aparece claramente ilustrada por la siguiente normativa dictada en los años ochenta por el Comité Nacional de Televisión: «La desnudez completa, de hecho o en silueta, no será permitida nunca», excepto en «escenas reales de los nativos de tierras lejanas» (Sierra, 2005). Esta afirmación constituye la explicitación de la distinción estética y moral entre lo que sería la obscenidad de una desnudez destinada a un consumo erótico o sexual (por «empatía» carnal hacia la imagen), y la puesta en escena científica de un desnudo destinado a un consumo puramente intelectual (en el espacio ideal del «juicio») ${ }^{4}$. Pero lo interesante es que se opera esta distinción aplicando un corte etnológico sobre el continuo antropológico de la desnudez humana. Ahora bien, si revisamos la constelación de producciones etnográficas de fines del siglo XIX y de gran parte del siglo XX, constatamos la aparición de una faceta de la etnografía que podemos calificar de "efectivamente» pornográfica, en la medida en que remite a ese potencial afrodisíaco de la imagen, es decir a la producción de un efecto en el espectador. Así, la norma del Comité Nacional de Televisión funciona casi como una denegación de esta dimensión erótica o sexual inmanente al documento etnográfico. Ésta ha sido relevada en otros trabajos que, por ejemplo, han estudiado el problema de la pose en estas fotos etnográficas. En muchos

4 Para una lectura crítica de esta oposición entre desnudo / desnudez en la estética, ver Didi-Huberman (2005: 24 y ss). 
de estos retratos marcados por la convicción de mostrar «escenas reales de nativos de tierras lejanas», autores como Gastón Carreño reconocen en la pose de los y las modelos exóticos, la intervención del etno-fotógrafo. De hecho, estas poses pueden encontrarse en las producciones fotográficas eróticas o pornográficas (evitaremos por el momento el necesario desarrollo de esta distinción) que circulaban en las sociedades occidentales de la época (láminas 2 y 3) (Carreño, 2002).

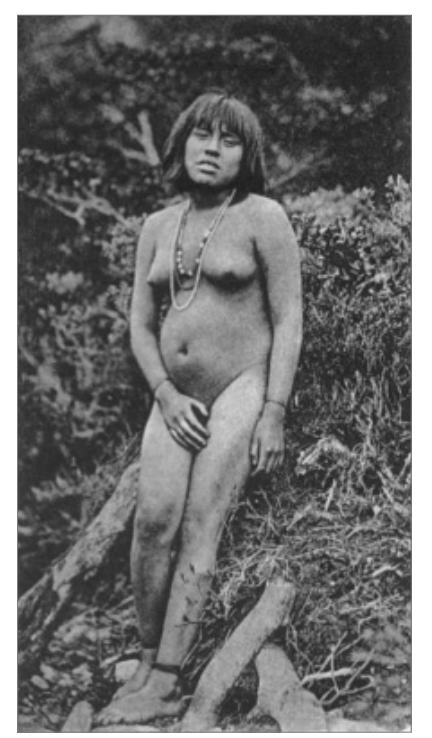

2. Kamanakar Kipa 1882-1883. Fuente: Paul André (ed.). (1995). Cap Horn. Recontre avec les Indiens Yahgan. Colection de la Photothèque du Musée de l'Homme. París: Ed. De La Martinière.

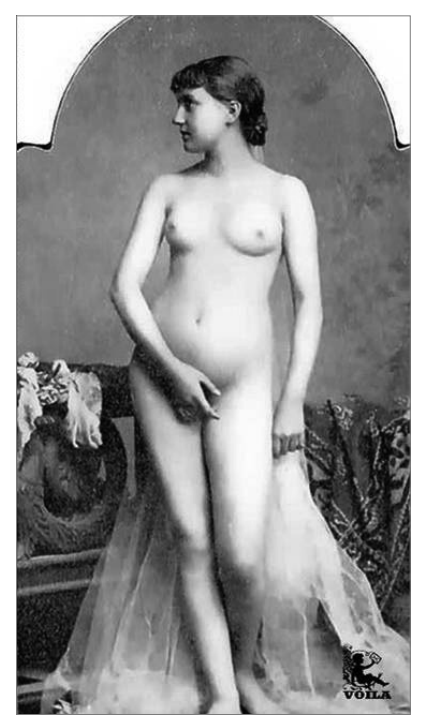

3. Postal erótica, circa 1880. Fuente: sitio web: Voila e-cards from the past. (2009). Consultado el 14 de Julio desde <http://www.vintagelovelies.com/cabinet/eroticphoto/91>. 
Esta inflexión erótica, por la que el desnudo etnográfico deviene desnudez empática, implica una variación de la zona de indeterminación antropológica. Tras la deshumanización zoológica del análisis antropométrico, refluye esta forma paradójica de humanización por la que se acciona un tratamiento humano basado en una común inhumanidad, muchas veces interpretada como el sustrato de animalidad que definiría una unidad zoológica del género humano. A diferencia de la división de lo humano en grados de animalidad interna operada por el tratamiento antropométrico y formalmente pornográfico de la imagen etnográfica, la etnografía, en su faceta efectivamente pornográfica, repone una animalidad que une a lo humano por fuera. Esta forma de la indeterminación produce, por ejemplo, la paradoja siguiente: si por el porno la mujer blanca deviene «objeto sexual", y por lo tanto se le puede considerar como deshumanizada, la mujer indígena es humanizada cuando se le aplica el tratamiento pornográfico que deshumaniza a la mujer blanca.

Una tercera característica que comparte el imaginario etnográfico con el pornográfico es su tratamiento de los nombres propios. En ambos casos los personajes representados no sólo ven disgregados los límites de su corporalidad como soporte de una identidad subjetiva, sino que ésta es obliterada también por la ausencia total o relativa de nombres propios, en tanto asignadores de una identidad individual. Disuelta en anonimia como en unanimidad, la individualidad es subordinada a las categorías colectivas de la raza, el sexo, la anatomía o la enfermedad. Se trata de una operación de "anonimalización", por la que el sujeto individual es devuelto a la categoría animal del ejemplar. Más allá de la pornografía y de la etnografía, este tratamiento del nombre propio remite a una vasta gama de usos de la fotografía con pretensión científica. En su análisis del montaje fotográfico de la histeria realizado por Charcot a fines del siglo XIX, Didi-Huberman reconoce este mismo gesto como un registro médico del sujeto devenido ejemplo o ilustración de la enfermedad: La leyenda de este grabado (lámina 4) designa menos un atributo del referente («melancólica») que un concepto («Melancolía») cuyo referente, quiero decir esta loca en particular, no sería más que el atributo (1982: 46).

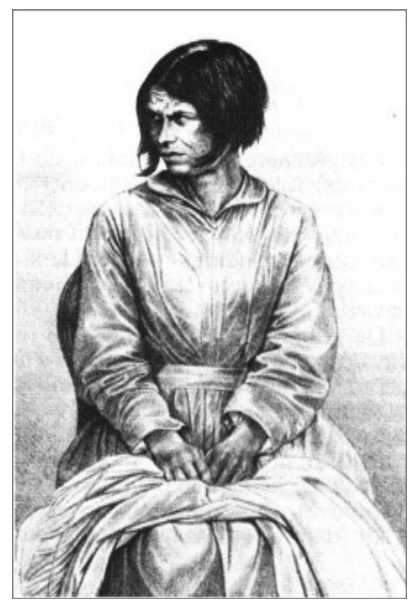

4. Grabado publicado con el título «Melancholy passing into Mania», en Medical Times (1858).

Fuente: Georges Didi-Huberman (1982). 
Algo similar ocurre con cierto imaginario etnológico de lo mapuche en el que la identidad individual de los personajes fotografiados es obliterada por la indicación general de la leyenda «indios araucanos» o simplemente «mapuche». Parafraseando a Didi-Huberman podemos decir que la mujer anónima de la fotografía (lámina 5) funciona como un atributo de la araucanidad señalada en la leyenda.

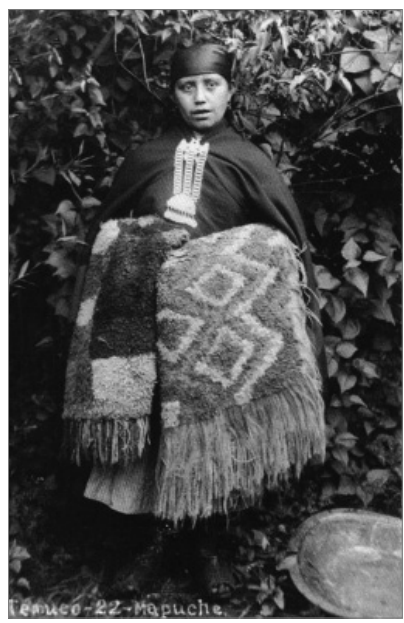

5. «India Araucana». Fuente: Alvarado, Margarita, Pedro Mege y Cristián Báez (eds.) (2001). Mapuche. Fotografías siglo XIX y XX. Construcción y montaje de un imaginario. Santiago: Pehuén.

Este imaginario etnológico ha sido ampliamente trabajado por Margarita Alvarado y su equipo. Aquí quisiéramos compararlo con otro imaginario, el imaginario alternativo que hemos identificado en el álbum de la Misión Anglicana de Kepe, presumiblemente hecho por el pastor canadiense Charles Sadleir (Menard y Pavez, 2007). Se trata de indagar en la idea de raza que está funcionando en cada uno de estos imaginarios. Para ello seguiremos la pista abierta por la Sociedad Secreta Reche en torno al lugar de la mujer, y más precisamente, del cuerpo y el pudor en una representación étnica o racial.

\section{EL PUDOR Y LA REPRESENTACIÓN DE LA RAZA}

La instalación de este imaginario folklorizante o exotizante, poblado de personajes anónimos y étnicamente determinados, coincide con la culminación del proceso de conquista militar de los territorios mapuche por los Estados chileno y argentino. Éste es el contexto en que, junto con los paradigmas racistas y racialistas que sostuvieron los proyectos coloniales de fines del siglo XIX, aparece la antropología moderna. Así, a este imaginario etno-fotográfico de lo mapuche le corresponde el surgimiento de una etnología mapuche, en la que ocupará un lugar de especial importancia la figura de Tomás Guevara. El surgimiento de este saber científico sobre lo mapuche se enmarca en la urgencia política de concretar en términos culturales y, como veremos, raciales, la incorporación no sólo 
de los territorios sino que también de las poblaciones mapuches a la soberanía nacional
chilena. Esta urgencia aparece a lo largo de la obra de Guevara en la tensión entre el convencimiento de la inexorable extinción de una raza inferior, y la esperanza de su incorporación, por chilenización, a la civilización. Así, en 1908, escribía:

[Protejida la raza indíjena] Los caracteres peculiares del araucano se irán alterando, pues en el curso de una o dos jeneraciones mas hasta se borrarán en grado mayor o menor ciertas diferencias profundas de las dos razas. El cruzamiento que ántes había sido malo para ámbas, dará en adelante un tipo mejor que los anteriores, por las condiciones sociales distintas en que se habrá producido (1908: 404). ${ }^{5}$

Esperanza de un Guevara laico que, a su vez, prosigue la esperanza centenaria del proyecto de integración encarnado por las misiones católicas que intentaron instalarse en el territorio mapuche desde la época colonial. De esta forma, podemos decir que más allá de sus diferencias, Guevara y los misioneros católicos del siglo XIX compartían el ideal de una integración de los mapuches a la nación chilena, por el mestizaje. De ahí la preponderancia que tomará en ambos casos la sexualidad: el proyecto de integración mestiza implica un conocimiento y un disciplinamiento de las sexualidades en tanto materia prima e instrumento en la producción de un sujeto mestizo.

Así, Guevara desplegará en su obra una minuciosa sexografía que en cierta forma participa de un género desarrollado con bastante anterioridad en la literatura misional católica. ${ }^{6}$ Encontramos a lo largo de su obra copiosas descripciones de juguetes sexuales, afrodisíacos, prácticas masturbatorias y otros tantos estigmas de una raza con bajo de nivel de «desarrollo moral». Se trata en definitiva del problema de una carencia de pudor, medible, entre otras cosas, por la frecuencia de sus desnudeces. En su Psicolojía del Pueblo Araucano de 1908, Guevara escribía:

A causa de la deficiencia del sentimiento del pudor, no se ocultaba la desnudez transitoria cuando las mujeres se bañaban, amamantaban a su hijo o en otras muchas ocasiones de la vida ordinaria i cuando los hombres dormian en el verano medio desnudos. A fuerza de ser un hábito, no hacia esperimentar excitaciones sexuales esta desnudez ocasional (42).

Esta referencia al amamantamiento nos remite a cierta proliferación de fotografías de mujeres mapuches amamantando en el corpus fotográfico exotizante (lámina 6). De esta

Tanto en esta cita como en las siguientes, se respeta la ortografía original del documento.

Destaca un confesionario redactado por el misionero franciscano fray Antonio Hernández Hernández Calzada a mediados del siglo XIX y que forma parte originalmente de una reedición del célebre Arte de la lengua general del Reyno de Chile, publicado por el jesuita Andrés Febrès en 1765, en el que, acumulando «adiciones y correcciones» Hernández, por momentos, se aleja ostensiblemente del original. Así por ejemplo, su versión del sexto y noveno mandamiento del confesionario es cinco o seis veces más extensa que la versión original de Febrès. En ella retoma los pecados y las variantes principales propuestas por el jesuita del siglo XVIII, multiplicando eso sí preguntas en reiteraciones y contrainterrogaciones del tipo: «P.-¿Has reparado á los animales cuando se juntan?/P.-¿Has reparado cuando se juntan los animales vacunos, los pájaros, u otros?/P.-¿Y entonces sentiste alguna alteración carnis vel pollutionem? (sic)/ P.¿Les has dado remedio á las mujeres, para que te quieran? / P.-¿Les has mirado con atención las partes pudendas, á las gentes o a los animales?/ P.-¿Y tu también sin necesidad te las has mirado? / P.-¿`Tocaste á alguno impudice in partibus pudendis? / P.-¿Has hecho eso con hombres ó con mujeres, ó con animales? / P.-¿Cuándo tocaste á alguno inhoneste, tuviste polución? / P.-¿Y entonces, ¿tuviste alteración ó polución? / P.-¿Polución te resultó? / ¿- ¿Y tu también contigo mismo tuviste tocamientos impúdicos? / P.-¿Y cuando tuviste estos tocamientos, tuviste polución? / P.-¿ंTienes acaso esa costumbre?» (en Schüller, 1907: 40). Cabe preguntarse cuántas de estas faltas corresponden a prácticas sexuales efectivamente constatadas en la Araucanía de su tiempo y cuántas a la creatividad del sacerdote. 
forma, si tomamos las dos dimensiones de la foto etnográfica (la formalmente y la efectivamente pornográfica) Guevara estaría moviéndose en la segunda, al declinar la diferencia racial en la diferencia que opone el plano común de la animalidad sexual, el instinto y la voluptuosidad, al pudor civilizado. Junto con esta caracterización sexualizada del "pueblo primitivo", este imaginario opera sobre la idea de la extinción como horizonte inevitable de la raza debida a una conjunción de falta de nacimientos, degeneración por el alcohol y "predisposiciones morbosas, más abundantes en la sociedad araucana que en la civilizada» (164-5).

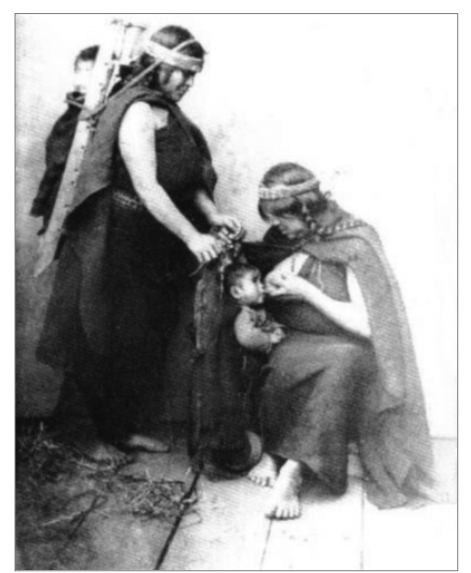

6. Mapuche amamantando. Fuente: Margarita Alvarado, Pedro Mege y Cristián Báez (eds.) (2001). Mapuche. Fotografías siglo XIX y XX. Construcción y montaje de un imaginario. Santiago: Pehuén.

La respuesta política a esta situación pasa nuevamente por el expediente sexual del mestizaje. De ahí la preocupación de Guevara por la baja proporción de matrimonios mixtos mapuche/chilenos y por la desvalorización de los sujetos mestizos:

En esta circunscripción de Tolten los mapuches poco o ningún interés tienen por mezclarse con los chilenos; juzgo que por no perder sus costumbres i su idioma, Manifiestan cierta tirria hacia los mestizos; que son pocos, i a quienes desprecian por su media sangre (160).

Aparecen aquí amalgamadas en un mismo plano la que podríamos llamar la dimensión cultural de las costumbres con la dimensión racial de los cuerpos y su reproducción. Cuando en 1898 el mismo Guevara escribía: "La comunidad de idiomas y el pantalón constituyen factores importantes, nimios al parecer, en el entrecruzamiento de las razas» (136), estaba postulando desde otro lugar el problema de la continuidad corporal entre raza y costumbre, de modo tal que el uso mismo de la vestimenta ya constituía una forma del cambio racial. ${ }^{7}$

Quisiéramos hacer ahora un contrapunto entre este imaginario y el que aparece en un álbum fotográfico realizado en la misma época, pero en el contexto misional anglicano. Como lo hemos señalado en otros trabajos, este álbum, presumiblemente realizado por

Sobre la sexología araucanista de Tomás Guevara y su relación con los discursos etnológicos y criminológicos de la época, véase Pavez, 2005. 
el reverendo Charles Sadleir, narra la instalación de la Misión Araucana en la localidad de Kepe presentándola como una suerte de gesta civilizadora y modernizadora articulada sobre la implementación de todo un aparataje tecnológico industrial, cultural y vestimentario. Antes de alinear las diferencias entre este imaginario anglicano y el imaginario etnográfico más difundido, es necesario señalar un momento heterogéneo en la narración del álbum. Se trata de una fotografía de Obder Haeffer, la única fotografía del álbum no producida en el marco de la misión, y en la que posan una pareja ataviada con joyas y trajes tradicionales mapuche junto con una niña que sostiene un cultrún. En los márgenes de la fotografía se lee la leyenda escrita seguramente por el reverendo Sadleir: "Indian youth in their native costume and condition» y a un costado: «Raw material» (lámina 7) (Menard y Pavez, 2007: 116).

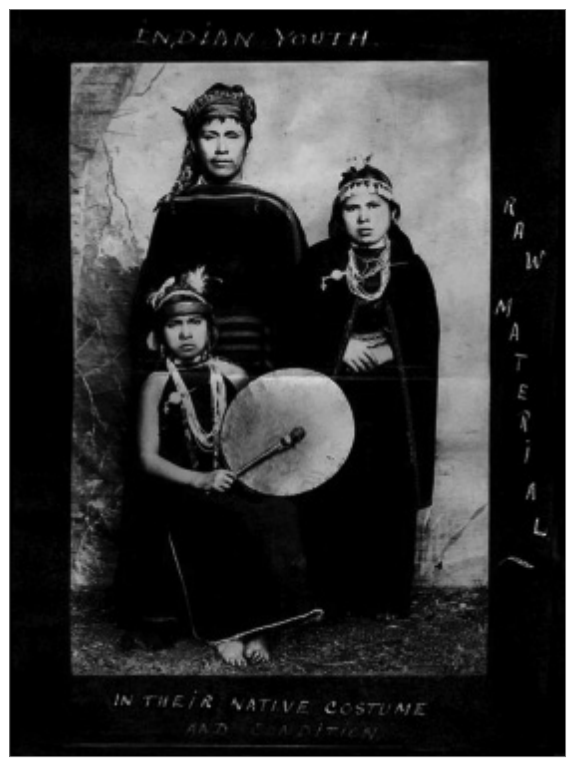

7. Obder Heffer. «Raw Material. Indian Youth in their native costume and condition».

Fuente: André Menard y Jorge Pavez (eds.) (2007).

El imaginario anglicano parece montarse sobre este fondo de raw material, material crudo o en bruto del que el álbum narrará el proceso de «cocción» cultural mediante su articulación con todo un arsenal de máquinas y tecnologías de la modernidad. Junto con las trilladoras y aserraderos mecánicos, turbinas eléctricas, imprentas y edificios, se pueden ver los numerosos internos e internas, las profesoras y profesores, así como algunos importantes caciques de la zona figurando como los personajes de una historia de contraste respecto de ese punto de crudeza ilustrada por el montaje etnográfico de Obder Heffer. De esta forma, en lugar del universo de indígenas de chiripa y chamanto, de mujeres descalzas, ataviadas de joyas y cultrunes, en casi todas las imágenes del álbum, niños y adultos mapuches aparecen vestidos a la occidental. Y en lugar de sujetos anónimos colocados en el rol de representantes etnográficos de una clase racial y colectiva, aparecen con sus nombres y apellidos (lámina 8). 


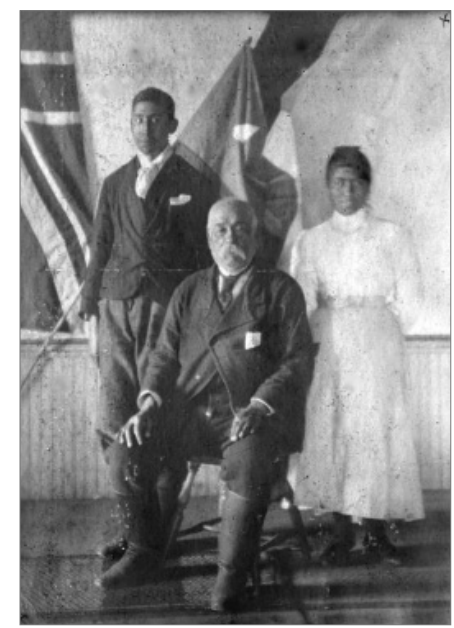

8. «The Chief Bernardo Namuncura and his children Justo and Marta», circa 1902.

Fuente: André Menard y Jorge Pavez (eds.) (2007).

En cierta forma la crudeza cultural ilustrada por ese raw material viene a cumplir una función análoga a la de la desnudez en el imaginario guevariano: éste requería de ella en tanto sustrato sexualizado de su proyecto de integración mestiza, en lo que aparece como un proyecto civilizatorio de la ropa para adentro, mientras que por su parte, el proyecto anglicano se planteaba de la ropa para afuera, mediante la cocción de una crudeza ajena a la común antropología de la desnudez. En el primer caso, la civilización de los mapuches pasaba por la reproducción mestiza de los cuerpos chilenos, en el segundo por la conexión de unos cuerpos mapuche racialmente intactos, a un aparato de producción industrial. En este sentido, no hay que olvidar que el régimen matrimonial al interior de la misión anglicana se regía por una rigurosa endogamia racial (anglosajones se casaban con anglosajonas, chilenos con chilenas, mapuche con mapuche). De ahí que más allá de las conversiones espirituales o las transferencias tecnológicas, la raza permanezca en el tiempo como una entidad diferencial no sujeta a cocción. Se trata de una raza que se moderniza y no de una modernidad que se racializa.

En 1911 ambos imaginarios entrarán explícitamente en conflicto a través de una larga polémica entablada entre Tomás Guevara y Charles Sadleir en el diario La Epoca de Temuco, a raíz de la publicación del libro Folklore Araucano de Guevara y más precisamente de ciertos proverbios eróticos allí recopilados. Detona el debate una reseña hecha al libro por el crítico Omer Emeth (seudónimo del sacerdote católico Emilio Vaisse), en la cual afirmaba que «de un análisis de aquellos proverbios dedúcese el escaso desarrollo moral de la raza que los creó», y añadía que tras la lectura del capítulo "Concepciones fisiológicas de los araucanos» (que al pasar trataba de "capítulo muy realista»), las «inmoralidades» descritas "contribuyen a explicar la rápida decadencia de la raza»: "Si al alcohol se junta, como es natural, una desenfrenada erotomanía, el mal es incurable. Los lectores del señor Guevara verán que aquellas dos plagas no fueron, como lo pretenden algunos, importadas por los conquistadores». Más allá de la pregunta por la realidad de estas descripciones y de estos juicios, la cuestión de fondo que tensará el debate tiene que ver con el problema general de la representación. 
Sadleir reaccionará escribiendo en representación «de varios araucanos», para impugnar la validez de esta representación etnológica y sexualizada hecha por Guevara y lo hará criticando justamente el criterio de representatividad que le subyace:

¿Sería justo formar un criterio de la raza chilena yendo a los prostíbulos y chineles de sus pueblos? [...] Averiguó nuestro autor entre la jente indíjena sana y decente las ideas araucanas, y no de jóvenes algunos de los cuales son semi-civilizados a quienes su contacto con la civilización que les rodea les ha quitado algo de la virilidad, la moral, la pureza de la vida araucana del campo (1911).

Son dos los elementos de esta respuesta: primero, que la civilización lejos de traer automáticamente la evolución moral, es más bien portadora de decadencia. Y segundo, que el verdadero lugar de la raza no debe ser buscado en su respectivo «bajo pueblo», es decir para el caso mapuche en aquellos sectores semi-civilizados y arrastrados por las derivas mestizogénicas anheladas por Guevara y los misioneros católicos. El lugar de la raza debe buscarse en aquel sector del mundo indígena provisto de "virilidad, moral y pureza", es decir en una suerte de aristocracia, que podemos deducir es encarnada por los caciques que Sadleir representa.

La contra-respuesta de Guevara apuntará a la refutación de estos dos postulados insistiendo, por un lado, en la "carencia de pudor en la mujer araucana» asociada al principio de que «el pudor es la resultante de la civilización de los pueblos», lo que explica el que «la mujer inferior amamanta libremente a su niño i descubre a veces las formas de su cuerpo sin ruborizarse por ello» (1911), acto escandaloso y que como vimos constituyó un motivo bastante recurrente en el imaginario etnográfico. Por otro lado, retoma el problema de la representación invirtiendo la perspectiva de Sadleir:

Réstame solo decir al señor Sadleir i a los dos o tres mapuches medio civilizados que representa, si es efectiva tal representacion, que los autores que estudian la raza desde sus orígenes no lo haran en ellos sino en el comun de los individuos, i que él ni ningun mapuche de ahora tiene derecho para protestar de un análisis étnico que se remonta a trescientos o mas años de esta fecha (Guevara, 1911).

En otras palabras Guevara opone al aristocratismo de Sadleir, una forma de populismo etnológico por el que la verdadera representación de la raza debe ser buscada en el estrato del "mapuche común», opuesto en su espontaneidad primitiva y falta de pudor, a los «dos o tres mapuche medio civilizados» que constituirían la élite representada por el pastor anglicano ${ }^{8}$.

El eje de la discordia se encuentra finalmente en la ambivalencia que habita el interior de la noción de representación. Resulta útil recordar aquí lo señalado por Gayatri Chakravorty Spivak (1988) respecto de los dos sentidos confundidos por este término (en inglés y en castellano) y que corresponden, por un lado, a la representación política

\footnotetext{
Encontramos resonancias de este populismo guevariano en los culturalismos posteriores, por ejemplo en la exaltación que hará Lévi-Strauss en 1956 de las sociedades «ágrafas» o "primitivas», las que si bien carecen de "producciones llamadas nobles", es decir de monumentos figurativos o escritos, cuentan con formas inmateriales del monumento: "A falta de estas producciones llamadas nobles, debemos, para conocerlas, acercarnos con igual pasión y con idéntico respeto, a las formas spopulares` de la cultura: aquellas compartidas entre todos los miembros de la sociedad, hasta los más humildes, al mismo título que el buen sentido del que hablaba Descartes» (1956: 386).
} 
del portavoz (vertreten en alemán) y por otro a la re-presentación mimética (artística o filosófica) del retrato, el concepto o la obra teatral (darstellen).

En este marco para Guevara el ejercicio de la representación política por parte de una élite mapuche ataviada con los signos de la civilización, implica dejar de ser plenamente re-presentativa en términos raciales o étnicos. Aparece la separación entre cultura y política que caracteriza cierta antropo-lógica identificable hasta el día de hoy en aquellos discursos referidos a los sujetos «étnicos» en tanto sujetos ejemplares y subordinados a la unanimidad del colectivo que deben, en primera instancia, re-presentar (darstellen). ${ }^{9}$ Por el contrario, desde el imaginario plasmado en el álbum anglicano, el hecho de que la élite mapuche funcione como el núcleo de pureza y verdad de la raza implica que los caciques, es decir los representantes políticos de la raza, re-presenten, en su elegancia occidental, a la élite winka (lámina 9). Contra el imaginario "crudo" de la chiripa y el chamanto y aún más lejos de las desnudeces del primitivo sin pudor, se despliega la serie de retratos de caciques de terno y corbata posando ante la cámara anglicana. De esta forma, la pregunta por la representación de la raza nos lleva al problema de la desnudez, la vestimenta y el disfraz.

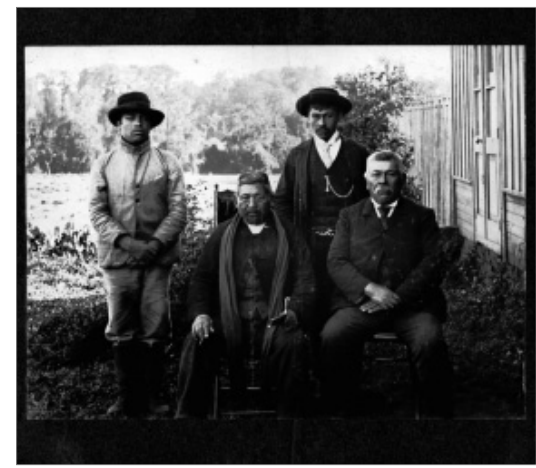

9. «Ambrosio Paillalef, Cacique of Pitrufquén, and Joaquin Millanao, Cacique of Lila, Loncoche», ca. 1900. Fuente: André Menard y Jorge Pavez (eds.) (2007).

\section{DISFRAZ Y DESEO}

Ahora bien, los retratos de estos caciques no registran tanto el espectáculo misional de su incorporación tecnológica y vestimentaria a la civilización, como la presencia de unos sujetos que, en lugar de un raw material humano exótico, prehistórico y pre-político, marcaban con su vestimenta occidental una inscripción política en la historia, sujetos que por lo demás, vestían así antes de la llegada de los misioneros. Podemos asumir por lo

Pensamos en las recurrentes críticas que se suelen dirigir a los representantes indígenas (y que no se suelen hacer a dirigentes políticos de otra índole) por el hecho de viajar a reuniones al extranjero, recibir recursos de instituciones internacionales o incluso utilizar teléfonos celulares. La posibilidad de tales críticas tiene que ver con la misma operación metafísico-racialista por la que representación política y re-presentación étnica, aparecen instaladas sobre un plano de exclusiones duales en las que se alinean la clásica serie de oposiciones escritura/oralidad, individuo/colectivo, conciencia/inconsciente, etc. 
tanto que en estos retratos hay algo que escapa al argumento narrativo misional (es decir a la historia de la instalación de un aparato de cocción cultural montado sobre la virginidad de una raza cruda y de chamanto), lo que no significa que remita a una realidad anterior a toda argumentación. Ese algo remite a una dimensión activa del retratado, una dimensión argumental (o contra-argumental) en la que la pose y la vestimenta indican el lugar de una representación política, que mediante o pese a esta re-presentación de la elegancia winka, materializa una verdadera y legítima representación de la raza, representación que se querrá plena y en todos sus sentidos.

Estos retratos constituyen la forma fotográfica de la dimensión aristocrática o nobiliaria que subyace al discurso de Sadleir y en el que podemos presentir la voz de los caciques que dice representar. En este sentido, caciques y dirigentes como Manuel Manquilef, Aburto Panguilef o Venancio Coñuepan recurrirán en más de una ocasión, y pese a las profundas diferencias políticas que los enfrentaban, a este argumento aristocrático como fundamento de sus reivindicaciones políticas, territoriales o culturales. Por lo demás resulta bastante evidente que entre la imagen dada por Guevara de una raza políticamente derrotada, biológicamente decadente y en vías de extinción, y la imagen de una raza dignamente representada por dirigentes aristocráticos, vestidos con moderna elegancia y convencidos de la vigencia de su autoridad, así como de una autonomía racial y política frente a la nación y al Estado chilenos, los caciques encontrarán en el proyecto anglicano una alternativa de negociación más atractiva que la ofrecida por el proyecto mestizo.

Por otro lado, encontramos una inversión de esta lógica de la re-presentación vestimentaria operada mediante este travestismo cacical, en la serie de fotografías que por la misma época retrataban a damas de la sociedad chilena, disfrazadas de mapuche (lámina 10). Esta comparación nos obliga, sin embargo, a aclarar qué estamos entendiendo por «disfraz» en cada caso. La seriedad, al tiempo que la naturalidad en la pose de los caciques puede contradecir la comprensión de su elegancia occidental bajo la lógica del disfraz, sobre todo si la contraponemos a la frivolidad que supone el gesto de travestismo indígena en las damas de la alta sociedad chilena. Pero la impertinencia de la noción de disfraz tiene sentido sólo si se considera que su función principal es la de esconder la verdadera identidad de un cuerpo, como sería el caso para las damas chilenas, lo que por lo demás justifica el examen indicial que les aplica Margarita Alvarado con el fin de definir, mediante la languidez de un gesto o el descuidado nudo de una faja, la verdadera raza de sus portadoras (2001: 22). Si por el contrario, se considera que la función del disfraz no es la de esconder sino que la de tomar vida o la de ser activado por el sujeto que lo ocupa (Viveiros de Castro, 2004: 65), podemos repensar la elegancia occidental de los caciques así como el tipo de "naturaleza" que subyace a la naturalidad con que la exhiben. La naturaleza de esta naturalidad variaría respecto de la naturaleza disimulada por las damas chilenas en la medida en que la naturalidad de los caciques remite a una naturaleza de otra índole, no a una naturaleza racial biológicamente dada, sino que a una naturaleza histórica y políticamente construida ${ }^{10}$. En un caso el disfraz disimula - y evidencia por

La dimensión construida de esta naturaleza la acerca más bien a lo que tradicionalmente se entiende como propio de la cultura por oposición a la naturaleza. Sin embargo, seguimos aquí la inversión esquemática propuesta por Viveiros de Castro a la hora de caracterizar cierta "cosmología amazónica» y en la que la cultura ocuparía el lugar de lo absoluto, como el punto de vista siempre humano y subjetivo, que puede ocupar y desplazarse por una multiplicidad de naturalezas relativas y susceptibles de construcción y manipulación. En este marco, el disfraz funciona como una de estas naturalezas corporales construidas y activadas por la subjetividad cultural en tanto punto de vista absoluto: «Se viste una ropa-máscara más 
desplazamiento - una verdad racial, mientras que en el segundo la verdad de la raza se materializa en el disfraz, disfraz que justamente registra histórica y políticamente su irreductibilidad a la homogeneidad biológica del humanismo mestizo. Más que un gesto de integración mimética, lo que los caciques hacen al re-presentar (es decir al disfrazarse de) señores winka (latifundistas, empresarios, generales o presidentes), pareciera tener que ver con la marca de una diferencia, la diferencia irreductible por la que los adversarios se vinculan y se equivalen en la guerra que los comunica.

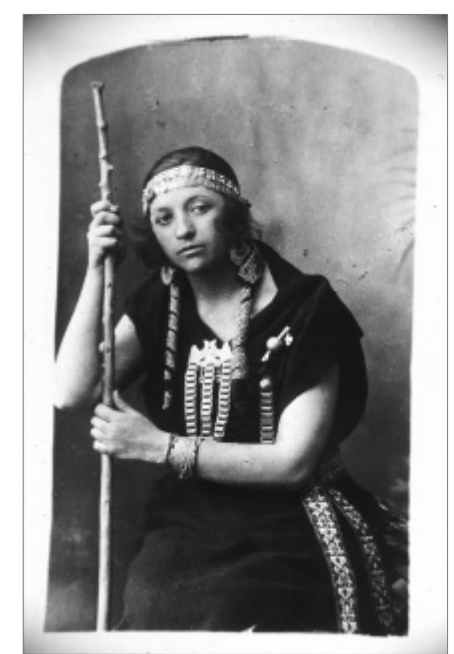

10. «Dama chilena con atuendo mapuche» (Formato Cabinet / Archivo Fotográfico University of Pensylvania, Museum Philadelphia). Fuente: Margarita Alvarado (2001: 15-27).

De esta forma, y mientras el disfraz de los caciques afirma la igualdad sobre la mutua diferencia, el disfraz de las damas chilenas simula una diferencia racial, pero que más allá de reafirmar por contraste la blancura disfrazada (como lo nota Margarita Alvarado), remite al pathos erótico de una indiferenciación sobre el ya comentado límite inferior de un humanismo sexualizado. En su simulacro indígena, las damas chilenas re-presentan una forma invertida del mismo fantasma erótico que identificamos en las fotografías etnográficas. La dama civilizada, suerte de templo viviente del pudor y del recato, se inclina hacia las crudezas inferiores de la salvaje y sus lubricidades y de esta forma activa la dimensión erótica que emana de la re-presentación de un sujeto blanco y femenino «mancillado» por el fantasma de la impudicia etnológica. Resuena en estas fotografías el denso imaginario decimonónico de las cautivas, así como el florecimiento en esa misma época de un estilo pictórico obsesionado con la imagen de la esclava blanca, desnudada, exhibida, tasada, manoseada e intercambiada por machos orientales. ${ }^{11}$ De hecho, se dará en Chile una conjunción de estos dos motivos en la serie de cuadros y grabados en los que

para activar los poderes de otro cuerpo que para ocultar una esencia humana bajo una apariencia animal» (65).

11 Véase por ejemplo los famosos cuadros de Jean-Léon Gérôme "Compra de una esclava» o «El mercado de esclavos", en los que un grupo de barbudos ataviados con túnicas orientales inspeccionan los dientes de una blanquísima mujer (¿una europea?) desnuda. 
desde Eduard Poeppig hasta Raymond Monvoisin, pasando por Mauricio Rugendas, se representa el rapto y el destino de las mujeres capturadas por los indígenas (o bandoleros) en sus malones (Del Valle Tabatt, 2006).

En 1884, es decir recién culminado el proceso de conquista de los territorios mapuches por los estados chileno y argentino, y en el momento en que las damas chilenas comenzaban a retratarse ataviadas como indígenas, Benjamín Vicuña Mackenna publica un breve texto sobre el caso de una de las más célebres cautivas (o presunta cautiva): Elisa Bravo. Esta joven madre había desaparecido el año 1849 en el naufragio del Joven Daniel frente a las costas de Puaucho. Surgieron entonces versiones según las cuales la tripulación, tras sobrevivir al naufragio, habría sido asesinada por los indígenas de la zona, menos la bella Elisa Bravo quien habría pasado a manos de algún cacique. Más de treinta años después seguían circulando rumores sobre gente que la había visto en algún lugar de la Araucanía. Si bien el texto de Vicuña constituye una refutación de estas versiones asegurando que Elisa Bravo nunca sobrevivió al naufragio, y que toda la historia del rapto responde a un juego de calumnias e intrigas entre caciques rivales (lo que no anula la utilidad política del mito pues habría justificado el definitivo sometimiento de los territorios indígenas a la soberanía chilena), se permite fantasear acerca del posible estado de la desdichada si efectivamente hubiera seguido con vida entre los salvajes: «¿Vive Cautiva Elisa Bravo, anciana y desnaturalizada ya por el infortunio, y la esclavitud, la promiscuidad de sus amos y sus años ya numerosos?» (Vicuña Mackenna, 1884: 33).

Y sugiere de esta forma la irreversibilidad de su pérdida más allá de su muerte efectiva. Es en este sentido que aparece la idea de una "desnaturalización», concepto complejo y que nos devuelve a la zona de indeterminación de lo humano que entrevimos más arriba en la normativa del Consejo Nacional de Televisión. Esta desnaturalización (como el término emparentado de una contra-natura) implica que en la caída al espacio extra o sub-cultural de la raza primitiva, donde se puede suponer una mayor cercanía con el ámbito de instintos y apetitos inferiores común a lo humano, habría un desvío respecto de la superioridad cultural o moral de una raza, devenida tal mediante su elevación por sobre este plano natural inferior. Lo interesante es que al describir esta desnaturalización de Elisa Bravo, Vicuña Mackenna termina remitiendo en última instancia a un destino del deseo. De hecho, parte preguntándose: «¿Mas [...] qué haría con su vida aquella infeliz señora? [...] ¿A quién podría amar y de quien ser amada?», e ilustra esta duda con un patético retrato:

Su prole habría de ser toda bárbara i reacia. Su belleza juvenil trocada en escarnio de senectud, su tez antes divina veríase convertida en rugosa corteza de raza bravía que se place en las bestialidades. Cambiando su dulce hablar en voces guturales; turbio el azul de sus ojos por los hielos o el fuego de la intemperie, convertidas en blanquecinas mechas su rubia y esplendente cabellera, encorbada, irritable, olvidada de la plegaria, convertida en idólatra y talvez, por el odio y la venganza en harpía [sic], un cruel cautiverio de treinta y cinco años, edad que para una mujer bella es mas de un siglo, su devoción a la vida de los cristianos, de los hogares y de los templos, sería para ella mas que una dicha, un sarcasmo, talvez una apostasía irritante de su fe... (35).

En su racismo de liberal positivista, Vicuña Mackenna invierte todo el optimismo misional católico que veía en la convivencia de indígenas y blancos un medio de integración. De hecho, supone en el cuerpo de una misma mujer y en el breve transcurso de treinta y cinco años, una forma concentrada de los procesos de degeneración que por esa épo- 
ca constituían uno de las principales preocupaciones del pensamiento social. Desde el célebre tratado del doctor Bénédict Augustin Morel y como una contraparte pesimista al optimismo del evolucionismo social, se vivía en la preocupación por los efectos degenerativos que los males sociales como el alcoholismo, la prostitución o la explotación industrial tenían en la población. Además, no hay que olvidar que según estas doctrinas el mestizaje también podía acarrear efectos negativos debidos a los peligros del atavismo, por el cual la mezcla de individuos de grados evolutivos diferentes podía dar por resultado un individuo con las taras y estigmas correspondientes al ancestro primitivo común a los dos progenitores. ${ }^{12}$ Pero recordemos que todo ocurre en el lapso de un cuerpo y de su vida, por lo que más que un problema de reproducción y de herencia, la desnaturalización de Elisa Bravo remite a un problema de contagio. Ahora bien, para que el contagio sea posible debemos suponer que más allá de su blancura y de su virtud civilizada, alguna predisposición tenía que existir. Una respuesta posible sería la de postular como medio fértil para este contagio a la propia feminidad, en tanto plano en sí mismo naturalizado por una razón patriarcal o machista. Pero algo más pareciera dibujarse cuando Vicuña Mackenna afirma que un "cautiverio de treinta y cinco años, [...] para una mujer bella es mas de un siglo». El problema ya no es sólo el de la feminidad en tanto serie de predisposiciones circunscritas a la mujer, sino que se trata de aquello que ocurre «a» una mujer, pero también «ante» una mujer en cuanto es bella. En esta frase Vicuña Mackenna explicita el plano sexual sobre el cual se sostiene la imagen de la cautiva. Si recordamos la primera pregunta: "¿de quién sería ya amada?», vemos que el problema para Vicuña Mackenna no sería tanto el del rapto de la cautiva, como el del rapto de su propio deseo. De ahí la ruptura voluntariosa entre un deseo civilizado y uno primitivo, una suerte de "arreduccionamiento" del deseo sexual que asegure la distinción entre sus naturalezas desiguales y prevenga posibles desnaturalizaciones. Y sin embargo toda esta voluntad de distinción es refutada en el párrafo siguiente al narrar su encuentro con una cautiva que, a diferencia de esta conjetural Elisa Bravo, sí logró escapar de su cautiverio. Se trata de «la bellísima castellana de Talca, doña Trinidad Salcedo, asaltada y robada por los feroces e impúdicos seides [sic] de Pincheira", a quien

aquellos demonios de la montaña, después de saciados, dejáronla siquiera en el abandono que le sirvió de rescate. Y entonces llena todavía de pudor, de belleza y de fé fue dueña de refujiarse en el santo claustro que lleva todavía su nombre - las Trinitarias de Concepción- y allí conocímosla nosotros treinta años más tarde, esbelta, arrogante y majestuosa todavía [...], pero rehusando alzarse el tupido velo negro del rostro hermoso delante de estranjeros. En aquella santa e infeliz mujer, la memoria del pudor violado había sobrevivido a todas las emociones de la tímida naturaleza femenina y aun a la obediencia que era lei de sus votos y de su juramento (Vicuña Mackenna, 1884: 35).

Y explica la última frase con una nota en la cual narra: «aunque el obispo Elizondo, que en esta ocasión nos acompañaba como a otros viajeros de Santiago, le rogó mostrase su rostro, que era todavía peregrino, al decir de su abadesa, rehusólo con gracia pero firmeza la monja talquina» (36). Es difícil imaginar algo más erotizado que ese cuerpo y ese rostro mancillados y luego velados. Lo demuestra la fascinación con que Vicuña Mackenna y el grupo de santiaguinos que acompaña el obispo insisten en verlos. De

12 Sobre el problema de la degeneración en el contexto europeo véase Pick, 1993, y para el caso sudamericano Ansaldi y Funes, 1991. 
esta forma, y más que la «tímida naturaleza femenina», lo que «la memoria del pudor violado» parece obliterar, mediante el velo y los muros del convento, es la continuidad de un deseo que comunica en un mismo plano erótico a Vicuña Mackenna con los indios y bandoleros que operaron la mancilla. Pero como en el caso del disfraz de las damas chilenas que junto con disimular, confirmaban su blancura, el velo de Trinidad Salcedo marca el límite del deseo a la vez que lo activa. Todo ocurre como si la emoción de Vicuña Mackenna ante ese monumento a la «memoria del pudor violado» no remitiera tanto a la invocación del pudor, como a la evocación de su violación.

Pese a la mestizofobia explícita de este liberalismo de fin de siglo, vemos cómo el texto de Vicuña, al igual que los retratos de las damas disfrazadas, ya bañan en el continuo sexual o erótico que constituye la materia prima del proyecto de integración mestiza que unos veinte años más tarde va a postular Tomás Guevara y al que Sadleir y los caciques que representa darán la espalda.

\section{UNA RAZA, VARIOS RACISMOS}

Lo anterior nos permite ver cómo las concepciones racistas y racialistas de cambio siglo estaban lejos de formar un bloque homogéneo, sobre todo en su relación con la noción de mestizaje. Para Tomás Guevara el mestizaje aparecía como un destino, un horizonte a alcanzar por la vía de una sexualidad visibilizada. En este marco el problema del pudor era enunciado por contraste con una desnudez explícita y sexualizada. Mientras que en el discurso de Sadleir (y posiblemente en el de los caciques que representaba), el mestizaje era obliterado bajo el velo de un pudor racial impermeable a las desnudeces y sus urgencias reproductivas. Encontramos una tercera variable de este pensamiento racial, pero sin duda más radical en su racismo, en el nacionalismo mestizofílico que comenzó a tomar forma en las cercanías del primer centenario de la república. El autor clave aquí es sin duda Nicolás Palacios y su muy difundida Raza Chilena de 1904. El problema del pudor y el de sus opuestos, la desnudez y la voluptuosidad, ocupan también para Palacios un lugar central en su reflexión sobre las identidades y las diferencias raciales. Él también dirigirá sus críticas contra la obra de Guevara (se refiere a la ya citada Historia de la Civilización de la Araucanía) que considera parte de una "cruzada contra los araucanos» (1988: 33) y en la que se reconoce el "propósito manifiesto de atacar la más pura de las virtudes domésticas araucanas: la castidad i el recato de sus esposas» (34). Tres años antes encontramos una carta dirigida a Rodolfo Lenz por un enigmático Curiñanco, que tenemos buenas razones para creer que se trata del mismo Palacios. ${ }^{13}$ La carta, coherente con las tesis desarrolladas en Raza Chilena, está motivada por la lectura de los Estudios Araucanos publicados entre 1895 y 1897 por Lenz, y en especial por ciertos «cantos licenciosos» allí recopilados. Curiñanco afirma:

Los cantos licenciosos son orientales, aun el de la trilla. Las orjias impúdicas solo entre la plebe se ven, i no con los caracteres que las describen algunos cronistas. Ud. no podria recitar ante Araucanos lejítimos i serios sus versos lascivos sin esponerse a su enojo, especialmente ante mujeres solteras, como no podría referir un fahelhafte geschichte de los car-

13 Agradezco a Jorge Pavez la comunicación de esta carta. 
gadores de hamburgo en presencia de ninguna familia alemana decente, i serian insensatez colejir de la moralidad jermana por esos cuentos.

Argumento que lo acerca al araucanismo pudoroso y aristocrático levantado por el reverendo Sadleir. Sin embargo, rápidamente constatamos tras este argumento el funcionamiento de una lógica más radical en su racismo, por ejemplo cuando dice: «Su Kallvün [el informante de Lenz] es mui hablador i hasta charlatan para ser Araucano. Se me figura que su índice cefálico es menos de 80 ». Recordemos que según Palacios la raza chilena sería la mezcla de dos razas patriarcales, y por ende superiores: godos y araucanos, a las que se opondrían las razas matriarcales inferiores: judíos y latinos en el caso de los primeros, huilliches en el de los segundos. De ahí que el índice cefálico menor a 80 indica un cráneo dolicocéfalo propio de un Huilliche matriarcal.

Tal como Guevara y Sadleir se criticaban mutuamente impugnando la representatividad de sus respectivos informantes, Curiñanco impugna la representatividad racial del informante de Lenz. Pero si Curiñanco se considera representante de la raza araucana, no lo hace, como Sadleir, en un sentido político de la representación (vertreten), sino que en el sentido mimético o etnográfico (darstellen) que da la comunidad de sangre: «El Araucano tiene su historia i su epopeya i no es posible atribuirle faltas ni defectos de otras razas sin que se falsee la etnografía en un punto que a los chilenos nos toca en nuestra sangre». De ahí que se permita firmar la carta con un nombre mapuche (práctica análoga a la edición anónima de Raza Chilena en la que sólo figura la indicación «Libro escrito por un chileno y para los chilenos»).

Sin bien Guevara y Sadleir parten de cierto esencialismo racial de lo mapuche: esencia pornográfica y plebeya en un caso, esencia recatada y aristocrática en el otro, en ambos funciona una variable de clase que tensiona la descripción meramente racial. En ambos casos se trata de una raza con diferencias y conflictos de clase en su interior: el araucano legítimo se opone al indígena semi o medio civilizado. Mientras que en Palacios no hay un afuera de la raza. Todo conflicto de clases debe ser interpretado en última instancia como un conflicto entre razas, y fundamentalmente entre una raza patriarcal superior y otra matriarcal inferior. En esto se diferencia de una noción nobiliaria de la raza - como la que estamos suponiendo en los caciques representados política y fotográficamente por Sadleir-, pues en lugar de un historicismo radical, supone un sustrato biológico sobre el cual es posible dividir y comparar una raza humana superior de una inferior. Por otra parte, se diferencia del racialismo de Guevara pues si para éste el mestizaje es un programa nacional y un destino racial, para Palacios el mestizaje funciona como un origen racial de la nación. ${ }^{14}$

Esta elevación arqueológica del mestizaje al rango de origen fundacional, sepulta la sexualidad bajo el peso de una épica. ${ }^{15}$ El dominio de Marte sobre Venus, según la expresión de Ercilla, se manifiesta en el racismo de Palacios bajo la forma de un elogio apolíneo del pudor patriarcal contra las desnudeces matriarcales. Es como si —a diferencia de la franca obliteración de la sexualidad en el discurso anglicano- el dato sexual apareciera,

14 Para una reedición de del debate entre Guevara y Sadleir, así como de la carta de Curiñanco, junto con una presentación más detallada ver Menard y Pavez, 2009.

15 Se trata de una continuación del gesto ercillano subrayado por José Toribio Medina en relación con cierta particularidad "que indudablemente llama a primera vista la atención en el poema de Ercilla», a saber: la voluntaria prescindencia que quiso imponerse en cosas de amor, y que desde un principio formalmente expresó: 〈Venus y amor aquí no alcanzan parte/ solo domina el iracundo Marte» (Medina, 1878: 44). 
pero lo hiciera en frío. Y de esta forma, cuando otros cultores de este racialismo nacionalista le quitan la ropa a un mapuche, en lugar de una desnudez buscan un desnudo. Pensamos aquí en los trabajos del profesor Leotardo Matus Zapata, quien en 1915 publicó en el Boletín del Museo Nacional, un artículo titulado "Instrucciones para el estudio de la antropolojía araucana». En él describía sus actividades de recolección de cadáveres en diferentes cementerios mapuche con el fin de efectuar mediciones antropométricas. El fin último de estas investigaciones era, según Matus, el contribuir a la realización de una descripción científica y definitiva de la «raza chilena» para "saber el lugar que nos corresponde ocupar en la tabla de desarrollo físico de los pueblos, tabla que hoi nadie conoce» (1915: 20).

Desde su perspectiva, que en este punto coincide con la de Palacios, se puede apreciar la distancia que los separa de la relación de exclusión que un positivista liberal como Vicuña Mackenna establecía entre su discurso y su deseo respecto del deseo y del cuerpo de un "otro". Se trata de una variación del proceso llamado a veces de descentramiento del sujeto que desde fines del siglo XIX vio entrar en escena a ese "otro del discurso" que encarnaba el cuerpo (De Certeau, 1975) y que fuera tematizado en términos de inconsciente o de instinto. Lo notable es que esta dimensión alterna y alteradora de la subjetividad podía implicar una profundización de los enunciados identitarios. De esta forma, la verdad del sujeto pasaba de la voluntad y la conciencia a estas esferas oscuras e interiores. En el caso de Matus el cuerpo como otro del discurso decimonónico se confunde con ese otro del discurso que encarnaba el indígena. Se opera así aquella incorporación de lo indígena (de lo «araucano» para ser más exactos) a los discursos conmemorativos de principios del siglo XX y su racialización mestizofílica de la identidad nacional.

El erotismo que acecha en los retratos de las damas disfrazadas de mapuche como en la obsesión de Vicuña Mackenna por la belleza mancillada de las cautivas, remite al vértigo de una disipación de la subjetividad civilizada y pudorosa en el plano a la vez zoológicamente ajeno y antropológicamente común de la lubricidad. Mientras que en la antropología nacionalista de Matus, la subjetividad misma del individuo se funda en la zona opaca de su raigambre racial. Así, un valor como el del pudor ya no remite a la adquisición de un logro cultural, sino que a la operación de los mecanismos instintivos que dicta el origen racial. ${ }^{16}$ En este contexto Matus se permite ilustrar su artículo con el retrato de unos jóvenes mocetones mapuche de torso desnudo (láminas 11 y 12).

16 Se trata de aquellas «cualidades instintivas, inmodificables por la educación» propias del «origen étnico» que enorgullecían a Nicolás Palacios (1988: 58). 


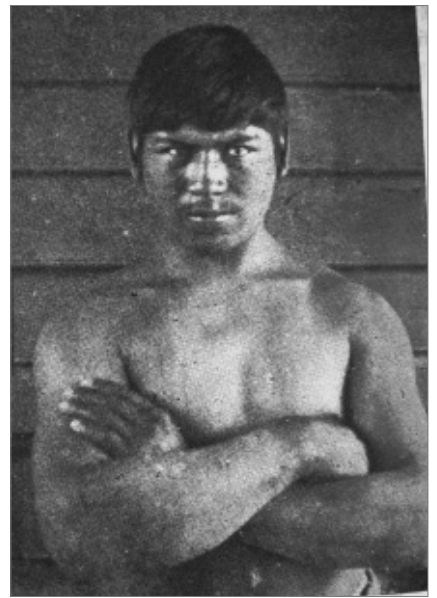

11. Joven mapuche. Fuente: Leotardo Matus (1915: 21-33).

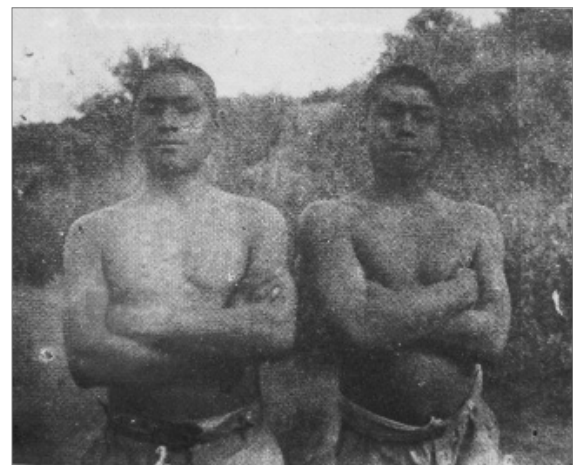

12. Jóvenes mapuches. Fuente: Leotardo Matus (1915: 21-33).

Contra el postulado de la desinhibición sostenido por el imaginario etnográfico y las tesis guevarianas, Matus afirma: "debemos decir que es difícil conseguir desnudar a un indio para medirlo o fotografiarlo. No creemos ser exagerados al afirmar, que talvez éstas sean las primeras fotografías al desnudo que se publican, de nuestros indios araucanos». Y prosigue explicando en forma irónica la función que estas fotografías cumplen en el texto:

Ellas muestran en detalle, la conformación física de los mapuches, dan a conocer el grado de desarrollo que alcanzan con su sistema de vida i muestran mas que todo, la dejeneración de la raza de que tanto se ha hablado entre las personas interesadas en desprestigiar a los indígenas (31).

Así, como Sadleir refutaba las tesis de la degeneración moral de la raza, estos retratos constituyen una refutación por la imagen de las tesis de su degeneración física, teniendo presente que desde el paradigma de la degeneración ambos aspectos se correlacionan. Y sin embargo Matus no produce una fotografía estrictamente antropométrica, mediante 
el recurso formalmente pornográfico del recorte y la medición del cuerpo indígena. ¿Se trata entonces de la producción de un sujeto étnico mediante una imagen efectivamente pornográfica? En parte sí, pero debemos reconocer su distancia respecto del imaginario sexualizado y de las desnudeces de un imaginario etnológico a la manera de Guevara. Se puede distinguir una pretensión de desnudo en estas desnudeces, ya que más allá de su efecto empático, poseen un valor demostrativo análogo al de la púdica elegancia de los caciques retratados en álbum anglicano: remiten a la dimensión intelectual de un juicio que, si bien es estético, plantea una evidencia ética y científica contra los postulados de una degeneración de la raza.

En línea con los postulados patriarcales de Palacios, la categoría intelectual o espiritual del desnudo (por oposición a la desnudez) aplicada a estos retratos se sustenta asimismo en la decencia que emana del aura de «virilidad» que buscan comunicar. Como bien lo ha notado Bernardo Subercaseaux, estamos aquí ante una construcción de género ampliamente difundida en los diversos círculos intelectuales y políticos de principios de siglo. Así, desde la Liga de Damas Conservadoras que en 1911 llamaban a combatir las malas costumbres y la inmoralidad con «los corazones llenos de temple viril», hasta las reseñas literarias en las que se celebraban talentos «de una vigorosa masculinidad», la virilidad remitía a un valor que, yendo más allá del rol sexual o de género, fomentaba la sobriedad y la claridad de un estilo opuesto a las "apariencias y los afeites cosméticos» (Armando Donoso citado en Subercaseaux, 2007: 98). Recordemos en este mismo sentido a Sadleir evocando «la virilidad» de la vida araucana del campo...

Pero como ya lo dijimos y pese a lo anterior, estas fotografías actúan también sobre la instalación de una desnudez explicitada en la violencia que el mismo Matus reconoce en su producción, cuando señala lo "difícil [que es] conseguir desnudar a un indio para medirlo o fotografiarlo» (Matus, 1915: 31). La mancilla etnográfica del sujeto etnologizado reencuentra así esas otras mancillas en que vibra el erotismo que estremeció a Vicuña Mackenna ante la monja y ex cautiva Trinidad Salcedo, o que subyacía a las descripciones etno-sexológicas de Guevara. Quizás en este caso, y tras la aparente frialdad apolínea de estos retratos, este erotismo funcione más bien como un homoerotismo necesario a la instalación de la masculinidad como horizonte arqueológico y teleológico, ético y estético de una raza devenida parámetro absoluto de lo humano.

En síntesis, esta instalación de la raza como ideal y norma no sólo política, sino que biológica, se opone a los proyectos anglicano y guevariano, en la medida en que para el primero la raza funciona como un dato explícito, y su infraestructura sexual como un dato implícito en su proyecto de productivización industrial de los cuerpos. Y se opone al de Guevara en la medida en que para éste la raza constituye un material de manipulación sexual subordinado a la producción de un orden político nacional. Cabe señalar por otra parte la articulación que un sector de la dirigencia mapuche de esa época estableció con la perspectiva anglicana, en función de su relativa afinidad con un proyecto de autonomía basado en un concepto de raza de fundamentos, eso sí, más históricos y políticos que biológicos. ${ }^{17}$

17 Es interesante notar que algunos dirigentes mapuche, como Manuel Manquilef en sus Comentarios del pueblo araucano (Manquilef, 1911-1914) o más tarde José Inalaf Navarro (1945), recuperaban los elogios racistas de Nicolás Palacios a la «raza araucana» para sostener sus propios, y muy diversos, discursos reivindicativos. Así mismo no está de más recordar que Leotardo Matus señalaba su amistad con Manuel Manquilef, y cómo éste lo acompañaba en sus empresas de recolección de cadáveres en los cementerios situados en tierras del cacique Fermín Manquilef, padre de Manuel. 
Pero en definitiva, lo que nos interesa subrayar es que estas diferentes perspectivas se tensan respecto de un mismo punto: el problema de representar la verdad de una raza. Por la filosofía sabemos que la verdad implica un velo y su develar, metáfora que en el caso de una raza recupera toda su literalidad. En este sentido, y más allá de su violento anacronismo, el escándalo de la Sociedad Secreta Reche ante la desnudez de las Malen Weichafe, devela la continuidad secular de una preocupación por la representatividad de la raza, que, pese a sus reformulaciones en términos culturales o étnicos, parece seguir remitiendo al juego de descubrimientos y ocultamientos que en última instancia remiten a las diversas posibilidades (desnudez, pudor, mancilla...) de un cuerpo y su presencia. Los distintos imaginarios que hemos logrado entrever, constituyen momentos posibles en este juego de representaciones de la verdad racial como verdad del cuerpo bajo la falsedad del disfraz, o, como lo sugiere el retrato de los caciques de terno y corbata, verdad del disfraz por sobre la idea de una desnudez natural, trascendente, verdadera.

\section{REFERENCIAS}

Alvarado, Margarita. (2001). Los secretos del cuarto oscuro y otras perturbaciones fotográficas. Revista chilena de antropología visual 1: 15-27.

Ansaldi, Waldo y Patricia Funes. (1991). Patologías y rechazos, el racismo como factor constitutivo de la legitimidad política del orden oligárquico y la cultura política latinoamericana. Terceras Jornadas Interescuelas/Departamentos de Historia de Universidades Nacionales. Buenos Aires: Facultad de Filosofía y Letras de la Universidad de Buenos Aires.

Carreño, Gastón. (2002). Fotografías de Cuerpos Indígenas y la Mirada Erótica: reflexiones preliminares sobre algunos casos del confín austral. Revista Chilena de Antropología Visual 2: 133-153.

Curiñanco, Ch. (1901). Carta a Rodolfo Lenz. Iquique, 29 de agosto 1901, documento inédito.

De Certeau, Michel. (1975). L'écriture de l'histoire. París: Folio.

Del Valle Tabatt, Francisca. (2006). El repertorio visual de las cautivas blancas en el siglo XIX. En Juan Manuel Martínez (ed.) Arte Americano; contextos y formas de ver (pp. 151-158). Santiago: Universidad Adolfo Ibáñez-Ril.

Didi-Huberman, Georges. (1982). L'invention de l'bystérie. Charcot et l'iconographie photographique de la Salpêtrière. París: Macula.

-. (2005). Venus Rajada. Buenos Aires: Losada.

Emeth, Omer. (1911). Folklore Araucano. La Época, Temuco, 4 de abril.

Guevara, Tomas. (1898). Historia de la civilización de Araucanía. Santiago: Imprenta Barcelona.

-. (1908). Psicolojía del pueblo araucano. Santiago: Imprenta Cervantes.

-. (1911). A renglón seguido. La Época, Temuco, 27 de abril.

Inalaf Navarro, José. (1945). Rol social, económico y político del indígena en Chile. Tesis de licenciatura Escuela de Derecho, Universidad de Chile.

Lévi-Strauss, Claude. (1956). Lettre au I Congrès d'artistes et écrivains noirs. Présence Africaine 8-9-10: 385-387. 
Manquilef, Manuel. (1911-1914). Comentarios del pueblo araucano. Anales de la Universidad de Chile vol. 128 y 131.

Matus, Leotardo. (1915). Instrucciones para el estudio de la antropolojía araucana. Boletín del Museo Nacional 8: 21-33.

Medina, José Toribio. (1878). Historia de la literatura colonial de Chile. Santiago: Librería Mercurio.

Menard, André y Jorge Pavez (eds.). (2007). Mapuche y Anglicanos, vestigios fotográficos de la Misión Araucana de Kepe, 1896-1908. Santiago: Ocho Libros-Laboratorio de Desclasificación Comparada.

- (2009). Raza y pudor en la pornología araucanista. Anales de Desclasificación: El animal pornográfico, 2, 1, en prensa.

Palacios, Nicolás. (1988). Raza Chilena. Santiago: Ed. Colchagua.

Pavez, Jorge. (2005). Deseo y dominación colonial. Ponencia en I Jornadas Internacionales de Pornología, Universidad de Valparaíso, 20-22 de julio.

Pick, Daniel. (1993). Faces of degeneration: a European disorder. Cambridge: Cambridge University Press.

Sadleir, Charles. (1911). Protesta Araucana. La Época, Temuco, 27 de abril.

Schüller, Rudolf. (ed.) (1907). Confesionario por preguntas y pláticas doctrinales en castellano y araucano por el R.P. Antonio Hernández Calzada. Santiago: F. Becerra Editor.

Sierra, Lucas. (2005). Tontos no pesados. El barómetro para los noticiarios no es censura. Es inútil, simplemente. El Mercurio, 21 de marzo. Obtenido desde <http://diario. elmercurio.cl/detalle/index.asp?id=\{c80191cc-a7db-4b0f-93e8-44ea7bc96e61 $\}$.

Spivak, Gayatri Chakravorty. (1988). Can the Subaltern Speak? En Cary Nelson and Lawrence Grossburg (eds.) Marxism and the Interpretation of Culture (pp. 271-313). Urbana: University of Illinois Press.

Subercaseaux, Bernardo. (2007). Historia de las ideas y de la cultura en Chile, tomo IV. Santiago: Universitaria.

Vicuña Mackenna, Benjamín. (1884). Elisa Bravo o sea el misterio de su vida, de su cautividad y de su muerte, con las consecuencias políticas i públicas que la última tuvo para Chile. Santiago: Imprenta Victoria.

Viveiros de Castro, Eduardo. (2004). Perspectivismo y multinaturalismo en Amazonía. En Surallès, Alexandre y Pedro García (eds.), Tierra adentro: territorio indígena y percepción del entorno (pp. 37-85). Lima: IWGIA.

Recepción: agosto de 2009

Aceptación: octubre de 2009 